\title{
Correlation between social media addiction and social media bullying: A cross sectional analytic study in Indonesian Youth
}

Ricky Indra Alfaray ( $\nabla$ rickyindraalfaray@gmail.com )

Oita University https://orcid.org/0000-0001-7721-9455

Yusuf Ibrahim

Universitas Airlangga

Rafiqy Sa'adiy Faizun

Universitas Sriwijaya

Laily Irfana

Universitas Muhammadiyah Surabaya

Primary research

Keywords: Social Media, Internet, Social Media Addiction, Cyberbullying

Posted Date: February 20th, 2020

DOI: https://doi.org/10.21203/rs.2.24034/v1

License: (1) This work is licensed under a Creative Commons Attribution 4.0 International License.

Read Full License 


\section{Abstract}

\section{Background}

Social media had eased communication among people in the last twenty years. However, the ease of being constantly connected also lead to problems, including social media addiction and social media bullying. Association between these two problems has not been researched extensively in Indonesia. Indonesia is the fourth most populous country in the world and said to be the most social media-addicted nation. Approximately $50 \%$ of the population is categorized as Youth Generation (Generation $\mathrm{Y}$ and $\mathrm{Z}$ ) who consider social media as a necessity in their daily lives. We conducted this nation-wide study to examine the correlation between social media addiction and the experience of being bullied in a social media platform in Indonesian youth.

\section{Methods}

An observational analytic study with a cross sectional design was conducted with a total of 1403 respondents. The samples were collected via consecutive sampling on Instagram. To determine social media addiction, the standard Social Media Disorder (SMD) Scale was used and the experience of being bullied is evaluated using a self-made questionnaire. Chi-square and Coefficient contingency analysis is used to determine the correlation.

\section{Results}

Almost half of the respondents $(n=671,47.9 \%)$ are classified as addicted to social media. More than half of the respondents claimed to have experienced bullying when interacting with people via social media $(n=923,66 \%)$. Analyzing the two nominal independent variables results in a weak yet significant correlation $(r=0.097, p=0.032)$.

\section{Conclusion}

There is a significant correlation between social media addiction and the experience of being bullied in a social media platform in Indonesian youth. Future research are needed to help government prevents social media addiction that proved has correlation with bullying.

\section{Background}

The latest generation of young people consisting of Generation $\mathrm{Y}$ and $\mathrm{Z}$ consider social media as a necessity in their daily lives. It is unsurprising that the use of social media platforms like Instagram, Twitter, and Facebook is increasing rapidly in recent years (1). As one the countries with the biggest internet user in the world, Indonesia was dubbed as one of the most social media-addicted nation in the planet (2). While the presence of social media has brought an abundance of positive impact to the world in terms of communication and business, the negative side of social media is just as apparent (3). The idea of Instagram, which is currently the fastest growing social media platform, is to share pictures and 
videos of users for other users to see either by following the said user or through hashtags associated with the posts. It currently has more than 400 million monthly active users and 80 million daily shared photos with 3.5 billion daily likes (4). The ease of being constantly connected with others by sharing what you are doing and seeing what others are doing could make a person dependent on the platform. This may lead some to social media addiction, which involves being unable to control social media use and using it to such an extent that it interferes with life tasks (5). Social media addiction is the compulsive use of a social media platform that manifests in behavioural addiction symptoms, including salience, tolerance, conflict, withdrawal, relapse, and mood modification (6). Aside from addiction, there are problems which create negativities arising from the content of the platform itself. The negativity is often explicitly seen in the platform through hateful comments or messages $(7,8)$. Comments made to specifically target the users are considered to be a form of cyberbullying. Cyberbullying is an aggressive intentional act carried out by a group or individual using electronic forms of contact repeatedly and over time against a victim who cannot easily defend him or herself (9). Others define cyberbullying as a form of humiliation and harassment associated with psychosocial problems including social anxiety, selfesteem, and depression (10-12). The prevalence rates of the matter varies between studies unfortunately as different studies have different interpretation on what could be considered as cyberbullying (13). Recently in Indonesia the number of children and adolescents who have experienced this form of bullying is high. One in ten parents reported that their children were abused in an online platform according to a survey of 24 countries including Indonesia performed by Ipsos in 2011 (14). A study by Safaria et al in 2016 also showed a worrying prevalence rate of cyberbullying occurring in Indonesia (15). These two harmful problems exist together but no extensive study had been conducted to examine the possible relation between the two. The fact that this form of bullying only occurs in an online setting indicate that there may be a connection between people who are dependent to the platform and the experience of being bullied online. We conducted this social media addiction study in a nation-wide scale, the biggest of its kind in Indonesia. The aim of this study is to examine the correlation between social media addiction and the experience of being bullied in a social media platform among Indonesian youth.

\section{Methods}

Study design and setting

We conducted an observational analytic study with a cross sectional design using an online questionnaire in social media. The questionnaire contains a list of questions related to the research title. The respondents in this study were followers of Instagram accounts rickyalfaray and rafiqy_sf. The Instagram account rickyalfaray has 41000 followers and an rafiqy_sf has 30000 . The samples were collected via consecutive sampling on willing participants from the followers of the two accounts.

\section{Participants}

The respondents were selected based upon their willingness to participate in the study. A total of 1452 respondents were collected and 1403 respondents were selected according to inclusion and exclusion 
criteria. The subjects included respondents from generation Y, born in 1980 s to mid-1990 s, and generation Z, born in mid 1990s to early 2000s (9). Participants who are unwilling to answer the provided questions are excluded from the analysis.

\section{Data collection instrument}

We collected the data using online self-administered questionnaire. The questionnaire was designed to collect comprehensive information and filled individually, with necessary confirmation of individual email to fill the form, taking approximately 15 minutes to complete the questionnaire. The questionnaire consisted of close-ended questions. Items for social media addiction contain a total of nine questions and items for feel of being bullied contain ten questions. Socio-demographic characteristics studied included gender, age, educational level and region where the respondents living. Standard Social Media Disorder (SMD) Scale consisting of 9 questions (10) was used to determine social media addiction. Experience of being bullied is evaluated using a self-made questionnaire consisting of 10 close-ended questions.

Data processing and analysis

Chi-square and Coefficient contingency analysis is used to determine the correlation between the samples with social media addiction and experience of being bullied. Each variable consists of two groups with a nominal data scale (yes and no) based on the questionnaire results. The analysis was performed using SPSS ${ }^{\text {Tw' }}$ version 25.0 .

\section{Ethical clearance}

The questionnaire was submitted for ethical review by the Medical Research Ethics Committee of Universitas Muhammadiyah Surabaya. The Medical Research Ethics Committee approved the questionnaire as instrument of data collection and forms of consent. The respondents were given information for consent regarding the purpose of the study and ensured confidentiality before answering the questions.

\section{Result}

Demographic of respondents

The respondents of the questionnaire come from a variety of age and education from all over Indonesia. Most of the respondents are from Java, more specifically East Java $(n=384,27.40 \%)$ and West Java $(n=$ $326,23.26 \%)$. Most respondents are in the range of $13-19$ years old $(n=994,70.94 \%)$ covering $71 \%$ of all respondents. Most of them are currently enrolling in a university or at least working with a university-level degree $(n=867,61.88 \%)$.

Social media addiction 
Almost half of the respondents ( $n=671,47.9 \%)$ are classified as addicted to social media based on the SMD Scale.

Social media bullying

More than half of the respondents claimed to have experienced bullying when interacting with people via social media $(n=923,66 \%)$.

Correlation analysis

Analysis of the two nominal independent variables results in a weak yet significant correlation $(r=0.097$, $p=0.032$.

\section{Discussion}

Teenagers born after the late $90 \mathrm{~s}$ tend to integrate technology and social media as part of their lives, at times rendering them impossible to live without being constantly connected (I). When using social media, there are two basic social needs; the need to belong and self-presentation (16). The need to belong is reflected on Instagram through the popularity motive. Previous study performed by Sheldon \& Bryant shows that one of the motivations of Instagram user is popularity or coolness. A tendency commonly seen in users is to reach a substantial amount of likes in their post. The parameters for popularity are the amount of likes gained as well as having a large number of followers. Additionally, their posts were used as a form of self-presentation (1).

Social media is a two-edged sword with particular advantages and disadvantages. Social media easily connects people for personal communications as well as business-related reasons. Proper use of the platform could increase productivity and efficiency in a society (17). Meanwhile, social media disadvantages exist in the shape of behavioural addiction tendencies existing in some of the users (18). People who constantly worry about being unable to connect to the internet may develop impulsive checking habits that could evolve into an addiction (6). While this addiction in the platform is still considered relatively new, Internet and social media addiction has actually been examined extensively over the years (19). Previous studies were arguing over existence of social media addiction even though there are clear behavioural addiction symptoms (18).

Due to the definition and measurement problems surrounding social media addiction as well as a growing body of evidence suggesting that social media addiction is an emerging mental problem, Van den Eijnden et al proposed a measurement tool of diagnosis named the Social Media Disorder (SMD) scale (20). We used the standard SMD scale and found that almost half of our respondents are suffering from a social media disorder. Most of them are teenagers in the range of 13 to 19 years old. The age range is in line with puberty, during which a person often wish to establish a presence. The urge to establish who you are in a society and to be seen as a person with a certain amount of popularity or status fuelled with raging hormones is the perfect motivation for a teenager to engage in social media. 
These motives of coolness or popularity were confirmed previous studies (1). "Popularity contest" among teenagers throughout middle school to a university level education has existed since before social media platform was even around (21). However, the existence of social media act as a helping hand, as it is easier for people to survey each other's daily lives through posts and updates. Additionally, most of our respondents are enrolling in a college or university level education, which may increase the dependency in the platform due to the current trend of using social media to carry out projects for communication and marketing purposes (22). Problem arises when a person is not able to perform daily productive tasks as he or she is constantly preoccupied by the artificial life in the platform (4).

Nowadays, being online is viewed as safer than hanging out on the streets. Parents assume using technology in the home as healthy. For young adults, sharing information on social media increases life satisfaction and loneliness (23). With the rise of internet and social media use, a new problem has emerged in the form of cyberbullying. Cyberbullying used to be underestimated by society compared to bullying that occurs in real life. The impact of cyberbullying should not be underestimated. The seemingly permanent state of the harassment in the form of text or images could harm a victim for a longer period of time compared to face-to-face bullying. The scale of cyberbullying is huge, with a staggering amount of half of the respondents claimed to have experienced a form of cyberbullying throughout their use of the platform $(n=923,66 \%)$.

We found a connection between two seemingly different standalone problems in social media. A person with social media addiction tendencies spend more time on the platform compared to a normal person. Thus, he or she is more prone to have experienced a form of bullying through hateful comments or messages (10). The experience may not only arise from the frequency of use, but also worsen by the motivation of using social media in the first place. A person who uses the platform to establish an identity and gain popularity would be more sensitive to negative statements made by strangers toward them (23).

This study indicates that a solution to lessen the negative aspects of social media should not only focus on one problem at a time. They often are connected and intensify each other. Based on the result of our study that for some people, it is possible that dealing with their social media addiction could also reduce the chance of being cyberbullied. However, we also understand that the problem of cyberbullying extends beyond finding a solution for the victims but also the perpetrator. The so called "trolls" intentionally spreading toxic messages to strangers is a whole other problem that should be assessed in a different study.

\section{Limitation}

Our study was conducted with cross-sectional design, with several inherent flaws. While our findings confirm correlation between social media addiction and social media bullying, definitive cause-and-effect between these two cannot be confirmed. Our questionnaire was self-reported, which may cause reporting bias. 


\section{Conclusion}

There is a significant correlation between social media addiction and the experience of being bullied in a social media platform.

\section{Abbreviations}

SMD

Social Media Disorder

\section{Declarations}

\section{Ethical Approval}

This study was approved by the Medical Research Ethics Committee of Muhammadiyah University Surabaya, Indonesia.

\section{Consent for publication}

Not applicable.

\section{Availability of data and materials}

The datasets used and analyzed during the current study are available from the corresponding author on reasonable request.

\section{Competing interests}

The authors declare that there is no conflict of interest.

\section{Funding}

This research did not receive any specific grant from funding agencies in the public, commercial, or notfor-profit sectors.

\section{Authors' contributions}

RIA, YI and RSF contributed in the conception and design of the study. RIA and RSF conducted the collection of data, with data analysis performed by RIA, YI, and LI. All authors contributed in writing the manuscript, with RIA and YI finalizing the manuscript for publication. LI helped with securing funding and supervision. All authors read and approved the final manuscript.

\section{Acknowledgements}


We would like to express our gratitude for Yudhistira P.K. and Indiarto A. P. and the support of the Universitas Muhammadiyah Surabaya.

\section{References}

1. Sheldon P, Bryant K. Instagram: Motives for its use and relationship to narcissism and contextual age. Computers in human Behavior. 2016;58:89-97.

2. Lim M. Many clicks but little sticks: Social media activism in Indonesia. Journal of contemporary asia. 2013;43(4):636-57.

3. Lim M. Freedom to hate: social media, algorithmic enclaves, and the rise of tribal nationalism in Indonesia. Critical Asian Studies. 2017;49(3):411-27.

4. Blackwell D, Leaman C, Tramposch R, Osborne C, Liss M. Extraversion, neuroticism, attachment style and fear of missing out as predictors of social media use and addiction. Personality and Individual Differences. 2017;116:69-72.

5. Blackwell D, Leaman C, Tramposch R, Osborne C, Liss M. Extraversion, neuroticism, attachment style and fear of missing out as predictors of social media use and addiction. Personality and Individual Differences. 2017;116:69-72.

6. Griffiths M, Kuss D. Adolescent social media addiction (revisited). Education and Health. 2017;35(3):49-52.

7. Lee E, Lee J-A, Moon JH, Sung Y. Pictures speak louder than words: Motivations for using Instagram. Cyberpsychology, Behavior, and Social Networking. 2015;18(9):552-6.

8. Sheldon P, Bryant K. Instagram: Motives for its use and relationship to narcissism and contextual age. Computers in human Behavior. 2016;58:89-97.

9. Grigg DW. Cyber-aggression: Definition and concept of cyberbullying. Journal of Psychologists and Counsellors in Schools. 2010;20(2):143-56.

10. Faucher C, Jackson M, Cassidy W. Cyberbullying among university students: Gendered experiences, impacts, and perspectives. Education Research International. 2014;2014.

11. Dehue F. Cyberbullying research: New perspectives and alternative methodologies. Introduction to the special issue. Journal of Community \& Applied Social Psychology. 2013;23(1):1-6.

12. Campbell MA, Slee PT, Spears B, Butler D, Kift S. Do cyberbullies suffer too? Cyberbullies' perceptions of the harm they cause to others and to their own mental health. School Psychology International. 2013;34(6):613-29.

13. Völlink T, Dehue F, Mc Guckin C, Jacobs NC. An introduction in cyberbullying research. Cyberbullying: Routledge; 2015. p. 3-14.

14. Safaria T. Prevalence and Impact of Cyberbullying in a Sample of Indonesian Junior High School Students. Turkish Online Journal of Educational Technology-TOJET. 2016;15(1):82-91.

15. Safaria T, Tentama F, Suyono H. Cyberbully, Cybervictim, and Forgiveness among Indonesian High School Students. Turkish Online Journal of Educational Technology-TOJET. 2016;15(3):40-8. 
16. Nadkarni A, Hofmann SG. Why do people use Facebook? Personality and individual differences. 2012;52(3):243-9.

17. Benedict C, Hahn AL, Diefenbach MA, Ford JS. Recruitment via social media: advantages and potential biases. Digital health. 2019;5:2055207619867223.

18. Andreassen CS, Pallesen S, Griffiths MD. The relationship between addictive use of social media, narcissism, and self-esteem: Findings from a large national survey. Addictive behaviors. 2017;64:287-93.

19. Hawi NS. Internet addiction among adolescents in Lebanon. Computers in Human Behavior. 2012;28(3):1044-53.

20. van den Eijnden RJ, Lemmens JS, Valkenburg PM. The social media disorder scale. Computers in Human Behavior. 2016;61:478-87.

21. Greenwood DN. Fame, Facebook, and Twitter: How attitudes about fame predict frequency and nature of social media use. Psychology of Popular Media Culture. 2013;2(4):222.

22. Whiting A, Williams D. Why people use social media: a uses and gratifications approach. Qualitative Market Research: An International Journal. 2013;16(4):362-9.

23. Teo WJS, Lee CS, editors. Sharing Brings Happiness?: Effects of Sharing in Social Media Among Adult Users. International Conference on Asian Digital Libraries; 2016: Springer. 